\title{
Father-to-Daughter Transmission of Focal Dermal Hypoplasia Associated With Nonrandom X-Inactivation: Support for X-Linked Inheritance and Paternal X Chromosome Mosaicism
}

\author{
Jerome L. Gorski \\ Division of Pediatric Genetics, Departments of Pediatrics and Communicable Diseases and Human Genetics, \\ University of Michigan Medical Center, Ann Arbor
}

Focal dermal hypoplasia (FDH) is a rare syndrome of severe developmental anomalies of the tissues and organs derived from ectoderm and mesoderm. Though data have suggested that FDH is an X-linked dominant trait associated with male hemizygote lethality, a hypothesis supported by the observation of three unrelated infants with FDH manifestations and de novo chromosome rearrangements involving Xp22, observations of father-to-daughter transmission have suggested possible genetic heterogeneity and autosomal dominant inheritance with sex limitation. We hypothesize that, if FDH is an X-linked disorder, cells expressing an active disease locus might experience a selective disadvantage resulting in a nonrandom pattern of $X$-inactivation in patient tissue. To test this hypothesis, we studied one of the two previously described families demonstrating father-to-daughter inheritance of FDH. To determine if the affected daughter had a skewed pattern of X-inactivation consistent with $\mathrm{X}$-linked inheritance of FDH, somatic cell hybrids were constructed by fusing hypoxanthine phosphoribosyl transferase (HPRT)-deficient rodent fibroblasts with either patient dermal fibroblasts or peripheral white blood cells (WBCs); hybrid clones retaining an active $X$ chromosome were analyzed to determine the parental origin of the active $X$ chromosome. Analyses of resulting hybrid clones showed that while hybrids constructed from skin fibroblasts contained an active $X$ chromosome inherited from either of the patient's parents, hybrids constructed from WBCs showed a skewed pat-

Received for publication August 1, 1990; revision received November 21, 1990.

Address reprint requests to Jerome L. Gorski, M.D., Division of Pediatric Genetics, 3570 MSRB II, 0688, University of Michigan, Ann Arbor, MI 48109-0688. tern of X-inactivation; 11 of 11 hybrids contained an active maternal $X$ chromosome $\left(\chi^{2}=12.2, P=.001\right)$. These findings indicated that, in this family, FDH was associated with a nonrandom pattern of $X$-inactivation consistent with $\mathrm{X}$-linked inheritance, suggesting that the patient's father was mosaic for a mutant FDH allele.

KEY WORDS: ectodermal dysplasia, somatic cell hybrid, developmental anomalies

\section{INTRODUCTION}

Several putatively X-linked diseases have been identified which primarily affect women [Wettke-Schafer and Kantner, 1983]. The reason for the observed excess of affected women has not been determined in most of these disorders. In some X-linked dominant disorders, the loss of hemizygous males has been well documented; for example, most males with severe ornithine transcarbamylase deficiency die shortly after birth. In other disorders, it has been assumed that the death of hemizygous males occurs during gestation; the observed excess of male spontaneous miscarriages in some kindreds segregating a putative $\mathrm{X}$-linked dominant trait has supported this presumption [Wettke-Schafer and Kantner, 1983]. However, the observations of similarly affected 46, XY males and kindreds demonstrating father-todaughter inheritance has suggested that some disorders may be phenotypically or genetically heterogeneous [Goltz et al., 1970].

One disorder that is predominantly limited to women is focal dermal hypoplasia (FDH) or Goltz-Gorlin syndrome (MIM 30560). This rare severe developmental disorder is characterized by focal areas of partial underdevelopment or thinning of the dermis with consequent herniation of subcutaneous tissue [Goltz et al., 1962]. Affected individuals have multiple congenital anomalies of tissues and organs derived from embryonic ecto-

(C) 1991 Wiley-Liss, Inc. 
derm and mesoderm including skeletal defects, eye anomalies such as colobomas and microphthalmia, and dermatologic abnormalities including linear hypo- or hyperpigmented macules, telangectasias, and papillomas [Freire-Maia and Pinheiro, 1984]. Though 95\% of FDH cases have been estimated to be nonfamilial, presumably representing new mutations [Fryns et al., 1978], two alternative modes of inheritance have been postulated. It has been proposed that FDH is an $\mathrm{X}$-linked dominant trait with male hemizygote lethality because most affected individuals are women, affected women experience an increased incidence of spontaneous midgestational miscarriages of male fetuses [Goltz et al., 1962], and four pedigrees have demonstrated mother-to-daughter transmission [Freeman, 1955; Wodiansky, 1957; Ginsburg et al., 1970; RuizMaldonado et al., 1974]. The observation of three unrelated females with manifestations suggestive of FDH and de novo cytologic abnormalities involving region Xp22 [Al-Gazali et al., 1990; Temple et al., 1990a] provides additional support that $\mathrm{FDH}$ is X-linked. Alternatively, an autosomal dominant sex-limited mode of inheritance was proposed [Goltz et al., 1970] based on the observations of multiple affected males and the observation of two pedigrees with father-to-daughter inheritance [Larregue et al., 1971; Burgdorf et al., 1981]; however, these observations did not exclude the possibility that the affected males were mosaic for FDH [Temple et al., 1990b].

Several X-linked disorders have been identified in which carrier women demonstrate a nonrandom pattern of X chromosome inactivation, presumably on the basis of a selective disadvantage to a subpopulation of cells with an expressed disease allele [Hall, 1988]. We hypothesize that, if FDH is an X-linked disorder, cells expressing an active disease locus might experience a selective disadvantage resulting in a nonrandom pattern of X-inactivation in heterozygote tissue. To test this hypothesis, we studied one of the two previously described families with demonstrated father-to-daughter inheritance of FDH [Burgdorf et al., 1981]. We now report our results which demonstrate that, in this family, FDH is associated with a nonrandom pattern of $\mathrm{X}$-inactivation consistent with $\mathrm{X}$-linked dominant inheritance and paternal $\mathrm{X}$ chromosome mosaicism for FDH.

\section{MATERIALS AND METHODS Cell Lines}

Dermal explants were dissected from sterile skin biopsy samples and cultured in standard conditions. Peripheral white blood cells (WBCs) were biopsied by venipuncture in heparinized tubes and separated from other cellular constituents by ficoll gradient centrifugation (LSM, Organon Teknika, Durham NC). Hypoxanthine phosphoribosyltransferase (HPRT)-deficient Chinese hamster fibroblasts, cell line RJK-88 [Fuscoe et al., 1983], were fused with human peripheral WBCs, and HPRT-deficient murine fibroblasts, cell line M613 [Kahan et al., 1974], were fused with human skin fibroblasts using polyethylene glycol as previously described [Gorski et al., 1989]. Independent somatic cell hybrid clones, one per plate, were isolated and maintained in DMEM media supplemented with $15 \%$ fetal bovine serum, penicillin-streptomycin $(100 \mu \mathrm{g} / \mathrm{ml}), 4$ mM glutamine, HAT $\left(10^{-4} \mathrm{M}\right.$ hypoxanthine, $10^{-5} \mathrm{M}$ amethopterin, $10^{-5} \mathrm{M}$ thymidine), and $1 \mu \mathrm{M}$ ouabain.

\section{DNA Isolation, Digestion, Blotting, and Hybridization}

DNA was isolated from cells by phenol/chloroform extraction of sodium dodecylsulfate (SDS) and proteinase K-treated cell lysates followed by ammonium acetate/ethanol precipitation [Hermann and Frischauf, 1987]. Restriction endonuclease digestions were performed by digesting $10 \mu \mathrm{g}$ aliquots of DNA to completion with a restriction enzyme per manufacturer's suggestions (Bethesda Research Laboratories, Bethesda, MD), as judged by minigel agarose electrophoresis. Digested DNA was fractionated by agarose electrophoresis, and depurinated DNA was transferred to Zeta-probe nylon membranes (BioRad, Richmond, CA) by alkaline transfer [Reed and Mann, 1985]. Radiolabeled probes [Feinberg and Vogelstein, 1983] were hybridized to the immobilized DNA at $65^{\circ} \mathrm{C}$ in $1.5 \times \mathrm{SSPE}$ [Maniatis et al., 1982], $0.5 \%$ nonfat dry milk, $1 \%$ SDS, and $100 \mu \mathrm{g} / \mathrm{ml}$ denatured salmon sperm DNA. Filters were washed at a final stringency of $0.1 \times$ SSC [Maniatis et al., 1982], $1 \%$ SDS at $65^{\circ} \mathrm{C}$, and exposed to Kodak XAR-5 film with an intensifying screen for 3-72 hours.

\section{CLINICAL REPORTS Patient 1}

The proposita had multiple skeletal and dermatologic anomalies at birth. She was the $2,800 \mathrm{~g}$ product of a normal uneventful 40 week gestation to a 33-year-old woman who had one previous pregnancy resulting in a normal male infant. There was no known exposure to recognized teratogens. Congenital anomalies included a coloboma of the right iris and retina, a hypoplastic right nasal ala, perioral papillomas, right hemiatrophy, multiple telangectasias, linear hyperpigmented macules, and linear streaks of dermal thinning with focal herniations of subcutaneous tissue. Her right hand had a single mobile digit with a normal nail and a second small flaccid digit located radially. Both feet had deep clefts. Medial to the cleft, both feet had normal first digits; lateral to the clefts, the right foot had two nailless syndactylous digits and the left had two digits curved plantarward. Roentgenologic examinations showed a hypoplastic right clavicle and osteopathia striata of the long bones; histologic examination of an atrophic macule showed normal stratified squamous epithelia with underlying adipose tissue and no discernible dermis [Burgdorf et al., 1981].

Her major motor development was normal, and at 12 years, she was in an age-appropriate class. Her major cutaneous defects have required numerous skin-grafting procedures to repair superficial ulcerations over atrophic regions (Fig. 1). She had a surgical revision of her right lacrimal duct and recurrent bilateral otitis media resulting in bilateral conductive hearing loss and necessitating bilateral tympanostomies and surgical ossicular chain repair. She had hypodontia; teeth were 
A

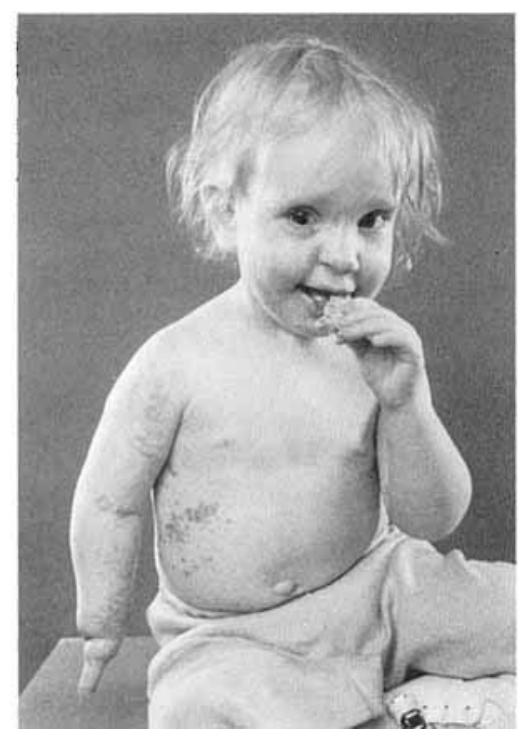

B

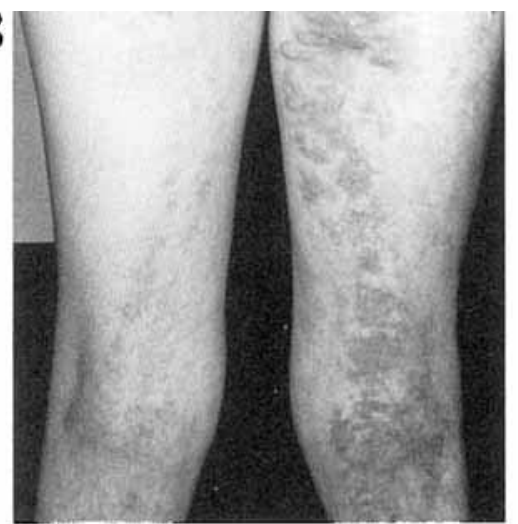

Fig. 1. Patient 1 at age 20 months (A) and the dorsal surface of her legs at age 14 years (B). Focal hypotrichosis, right inferiornasal coloboma, labial papillomas, right upper limb ectrodactyly, linear dermal atrophy in associated herniations of subcutaneous tissue, and linear hyperpigmented macules are shown.

dysplastic with hypoplastic enamel and were delayed in eruption. She had an atraumatic fracture of the left tibia and a surgically reduced dislocated of the right radial head.

Examination at 12 years showed all growth parameters below the 3rd centile with an occipitofrontal circumference (OFC) of $49 \mathrm{~cm}$, height of $129.5 \mathrm{~cm}$, and weight of $23.6 \mathrm{~kg}$. Additional findings included fine sparse hair with focal alopecia, right facial hemiatrophy, a highly arched palate, thoracolumbar scoliosis, and a narrow anterior-posterior thoracic diameter. Prometaphase chromosomal analysis showed a $46, \mathrm{XX}$ chromosomal constitution.

\section{Patient 2}

The father of Patient 1, a 54-year-old man of normal proportions, had linear telangectasias, atrophic dermal depressions, and streaked hyperpigmented macules of his right chest, abdomen, and leg recognized during infancy. The herniation of subcutaneous tissue beneath the atrophic lesions of his right axilla and inguinal region developed later in life (Fig. 2). When he was 14, he had a traumatic fractured left femoral epiphysis and right humerus. Roentgenologic examination failed to show osteopathia striata of his long bones; histologic examination of an atrophic macule from the forearm showed an absence of papillary dermis with fatty replacement [Burgdorf et al., 1981]. Physical examinations failed to show other stigmata of FDH; hair and teeth were normal, and his nails showed mild linear streaking which, though consistent with FDH, may have been acquired. He had a normal prometaphase karyotype showing a 46,XY chromosomal constitution.

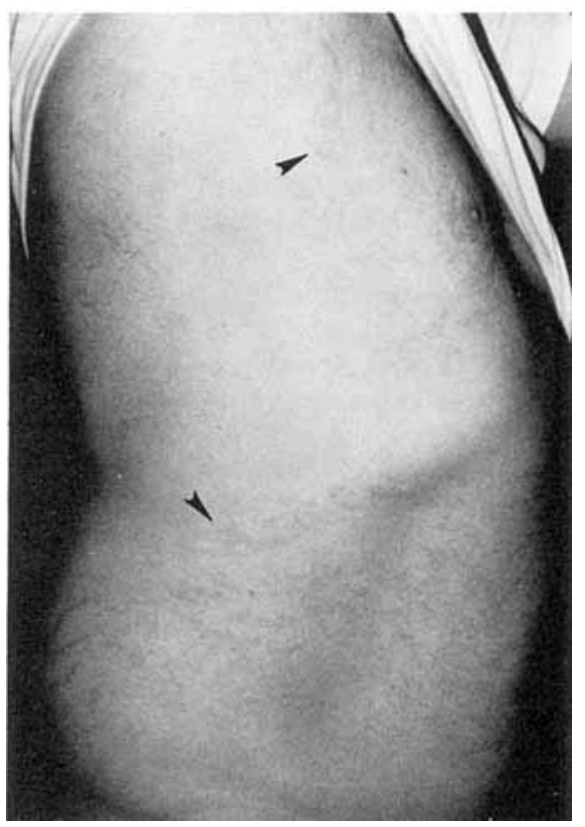

Fig. 2. A right lateral view of Patient 2 at 54 years of age showing multiple linear irregularly depressed hyperpigmented macules (arrowheads).

\section{RESULTS}

To distinguish the proposita's paternally and maternally derived $\mathrm{X}$ chromosomes, DNAs isolated from peripheral WBCs of the propositus (Patient 1), her mother, and her father (Patient 2) were analyzed using oli- 
goradiolabeled DNA probes detecting $\mathrm{X}$ chromosome restriction fragment length polymorphisms. Analyses showed that both the propositus and her mother were heterozygous for the DXS14 MspI polymorphism detected with probe p58-1. DNA samples from the propositus and her mother both contained the 3.8 and 2.4 kilobase (kb) alleles; the DNA of the proposita's father contained only the $3.8 \mathrm{~kb}$ allele, suggesting that the propositus inherited the $2.4 \mathrm{~kb}$ allele from her mother and the $3.8 \mathrm{~kb}$ from her father (Fig. 3).

In order to determine the parental origin of the active $\mathrm{X}$ chromosome in cells isolated from the propositus (skin fibroblasts isolated from an atrophic lesion and peripheral WBCs), somatic cell hybrids were constructed; biopsied cells were fused with HGPRT-deficient rodent fibroblast cell lines using polyethylene glycol. Somatic cell hybrid clones retaining a human $\mathrm{X}$ chromosome
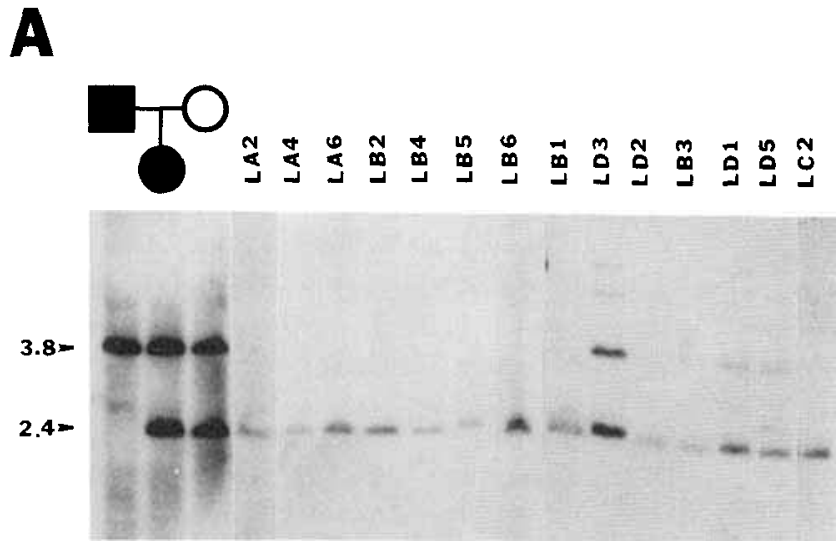

B

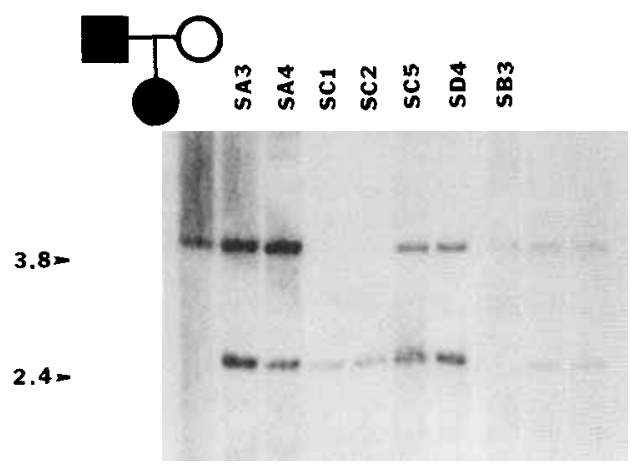

Fig. 3. Autoradiogram of oligoradiolabeled probe p58-1 hybridized to filters containing $10 \mu \mathrm{g}$ aliquots of $M s p I$-digested DNA. DNAs were isolated from either peripheral venous blood samples (lanes 1-3; panels $A$ and B) or somatic cell hybrids containing an X chromosome derived from Patient 1's white blood cells (WBCs) (A) (LA2-LC2; lanes 4-17) or skin fibroblasts (B) (SA3-SB3; lanes 4-10). Lane 1 contains DNA isolated from the father of Patient 1 (Patient 2); lanes 2, DNA isolated from Patient 1; lane 3, DNA isolated from the mother of Patient 1. Somatic cell hybrid cell lines derived from Patient 1's fibroblasts contain both the maternal $2.4 \mathrm{~kb}$ (SA3, SA4) and paternal $3.8 \mathrm{~kb}$ (SC5) DXS14 alleles (B). All somatic cell hybrid cell lines derived from $\mathrm{Pa}-$ tient 1's WBCs contained the maternal $2.4 \mathrm{~kb}$ DXS14 allele; none of the 14 isolated hybrid clones contained the paternal allele alone (A). bearing an active HGPRT gene were selected in HAT/ ouabain medium; to avoid clonal artifacts, only one hybrid clone per plate was isolated. Fusion experiments using dermal fibroblasts yielded 22 separate hybrid clones. Most hybrids derived from dermal fibroblasts were unstable during passage; DNA was isolated from only seven of the resulting hybrids. Fusion experiments using venous WBCs yielded 21 individual hybrid clones. Most of the isolated hybrid clones were stable upon passage; DNA was isolated from 14 different hybrids derived from venous WBCs.

To determine the parental origin of the active $\mathrm{X}$ chromosome retained in each of the resultant hybrid clones, hybrid DNA was digested with $M s p I$ and hybridized with probe p58-1 to identify the DXS14 parental allele present (Fig. 3). Somatic cell hybrids derived from the proposita's dermal fibroblasts contained both the maternal $2.4 \mathrm{~kb}$ allele (hybrids SA3 and SA4) and the paternal $3.8 \mathrm{~kb}$ allele (hybrid SC5); these results were consistent with a random pattern of X-inactivation within the proposita's fibroblasts. In contrast, in the somatic cell hybrids derived from the proposita's WBCs, 11 of 11 hybrids containing a single $\mathrm{X}$ chromosome contained the maternal $2.4 \mathrm{~kb}$ DXS14 allele (hybrids LD3, LD1, and LD5 contained both alleles). No hybrid clone contained the paternally derived DXS14 allele in isolation (Fig. 3). These results indicate a nonrandom pattern of $\mathrm{X}$ chromosome inactivation within the proposita's WBCs or progenitors; the proposita's maternal X chromosome was selectively active with an apparent deficiency in WBCs containing an active paternally derived $\mathrm{X}$ chromosome $\left.\chi^{2}=12.2, P=.001,1 \mathrm{DF}\right)$.

Attempts were made to verify these observations by using cloned expressed DNA sequences as probes to identify the parental origin of the active $X$ chromosome on the basis of differential methylation between an active and inactive $\mathrm{X}$ chromosomal locus [Vogelstein et al., 1985]; unfortunately, neither the propositus nor her parents were informative (polymorphic) at X-chromosomal loci (PGK or HGPRT) expressed in skin fibroblasts [Fearon et al., 1987] (data not shown).

\section{DISCUSSION}

These analyses sought to answer two interrelated questions regarding the genetics and biology of FDH: 1) Is FDH X-linked? and if so, 2) Are cells expressing a mutant FDH allele at a selective disadvantage? To address these questions, we used recombinant-DNA probes to study a family demonstrating father-todaughter inheritance of FDH and analyzed somatic cell hybrids retaining an active $\mathrm{X}$ chromosome derived from the affected daughter. Though an apparently random pattern of $X$ inactivation was observed in hybrids constructed from dermal fibroblasts, preferential $X$ inactivation of the paternal X chromosome was observed in hybrids derived from the proposita's WBCs. Within this family, these findings are consistent with the hypothesis that FDH was inherited as an X-linked dominant trait and that the proposita's father was mosaic for the mutant FDH gene. These findings suggest that the expression of a mutant FDH allele was associated with a selective disadvantage in hematopoietic cells. The mild 
clinical manifestations of the affected father are consistent with mosaicism and are similar to the mild changes observed in males mosaic for other X-linked, hemizygote lethal disorders such as ornithine transcarbamylase deficiency [Maddalena et al., 1988; Legius et al., 1990] and $\mathrm{X}$-linked agammaglobulinemia [Hendriks et al., 1989].

Significant evidence indicates that, within the cells of an inner cell mass, $\mathrm{X}$ chromosome inactivation is initially random, resulting in a mosaic population of cells; however, the proportion of the two mosaic populations may be subsequently skewed as a result of selection for alleles at loci influencing cell proliferation [Chapman, 1986]. In heterozygous women, the absence and presumed loss of cells expressing a mutant X-chromosomal allele is well documented: B cells expressing a mutant allele are absent from carriers of X-linked agammaglobulinemia [Conley et al., 1987; Fearon et al., 1987], abnormal platelets are apparently lost from Wiskott-Aldrich carriers [Gealy et al., 1980; Prchal et al., 1980], dermal fibroblasts expressing a mutant incontinentia pigmenti allele are underrepresented [Wieacker et al., 1985; Migeon et al., 1989], and HPRTdeficient hematopoietic cells are absent in carriers of Lesch-Nyhan syndrome [Albertini and DeMars, 1974]. In addition to providing a means to detect heterozygous women, these observations have assisted in providing information regarding the nature of the mutant gene product, the tissue in which the mutant gene is expressed, and the developmental pattern of gene expression and regulation. However, the demonstration of a nonrandom pattern of $\mathrm{X}$-inactivation has not necessarily provided a plausible explanation for a disease phenotype. For example, among heterozygotes, while the demonstrated deficiency of $\mathrm{B}$ cells expressing a mutant agammaglobulinemia allele corresponds to the disease phenotype of the affected hemizygote [Conley et al., 1987; Fearon et al., 1987], the absence of hematopoietic cells expressing a mutant HPRT in Lesch-Nyhan carriers does not correspond to the observed phenotype or play an obvious causative role in disease pathogenesis [Albertini and DeMars, 1974].

Our analyses of a family demonstrating father-todaughter transmission of FDH showed that, in somatic cell hybrids derived from the proposita's WBCs, the maternally derived $\mathrm{X}$ chromosome was preferentially retained. These findings suggest that mutations at the FDH locus may be detrimental to the proliferation of hematopoietic cells expressing the mutation, resulting in an underrepresentation of WBCs containing an active paternally derived X chromosome. Presumably, the loss of WBCs or precursors containing an active paternally derived X chromosome resulted from cell selection following random $\mathrm{X}$-inactivation. Because $\mathrm{X}$ chromosome inactivation patterns in females follow a binomial distribution curve [Fialkow, 1973], occasional normal females are expected to have apparently nonrandom patterns of $\mathrm{X}$-inactivation by chance alone. However, finding such a significantly skewed pattern of X-inactivation by chance, with selection against the paternally derived $\mathrm{X}$ chromosome in particular, is unlikely and provides new evidence that FDH is an X-linked disorder.

The observation that WBCs, but not dermal fibro- blasts, demonstrate a nonrandom pattern of X-inactivation suggests that in FDH, like HPRT deficiency [Albertini and DeMars, 1974], different cell types exhibit different tolerances toward a mutant disease locus. The apparent absence of nonrandom X-inactivation in dermal fibroblasts suggests that, unlike incontinentia pigmenti in which observed dermatologic anomalies have been proposed to be secondary to the loss of cells expressing a mutant allele [Wieacker et al., 1985; Migeon et al., 1989], the dermatologic anomalies observed in FDH may be associated with cells expressing a mutant FDH allele. Resolution of this issue will require the analysis of additional FDH patients and multiple tissues from affected and nonaffected areas.

We conclude that the nonrandom pattern of X-inactivation observed in the hematopoietic cells of the propositus of this family segregating FDH suggests, but does not prove, the existence of an X-linked locus for this disease. These analyses cannot rule out potential genetic heterogeneity, such as that recently demonstrated for Aicardi syndrome [Neidich et al., 1990]; further analyses with additional patients will be required to verify these findings. The potential application of such analyses to carrier detection and prenatal diagnosis will be dependent upon verification.

\section{ACKNOWLEDGMENTS}

We wish to thank the described family for their support and cooperation; Dr. D. Rucknagel for assistance in contacting the family; Dr. G. Bruns for cloned human DNA probes; Drs. C. T. Caskey and R. Nussbaum for cell lines; and J. Owens and J. LaPointe for assisting in preparing the manuscript. This work was supported in part by March of Dimes-Birth Defects Foundation Basil O'Conner Research Starter Grant 5-165 and National Institutes of Health (NIH) grant HD-23768 to J.L.G. J.L.G. is the recipient of NIH Physician Scientist Award K11-HD00788.

\section{REFERENCES}

Albertini RJ, DeMars R (1974): Mosaicism of peripheral blood lymphocyte populations in a female heterozygous for the Lesch-Nyhan mutation. Biochem Genet 11:397-411.

Al-Gazali LI, Mueller RF, Caine A, Antoniou A, McCartney A, Fitchett M, Dennis NR (1990): Two 46,XX,t(X;Y) females with linear skin defects and congenital microphthalmia: A new syndrome at Xp22.3. J Med Genet 27:59-63.

Burgdorf HW, Dick GF, Soderberg HD, Goltz RW (1981): Focal dermal hypoplasia in a father and daughter. J Am Acad Dermatol 4:273277.

Chapman VM (1986): X-chromosome regulation in oogenesis and early mammalian development. In Rossant J, Pedersen RA (eds): "Experimental Approaches to Mammalian Embryonic Development." Cambridge: Cambridge University Press, pp 365-398.

Conley ME, Brown P, Pickard AR, Buckley RH, Miller DS, Raskind WH, Singer JW, Fialkow PJ (1987): Expression of the gene defect in X-linked agammaglobulinemia. N Engl J Med 315:564-567.

Fearon ER, Winkelstein JA, Civin CI, Pardoll DM, Vogelstein B (1987): Detection of $\mathrm{X}$-linked agammaglobulinemia by analysis of $\mathrm{X}$-chromosome inactivation. N Engl J Med 316:427-431.

Feinberg A, Vogelstein B (1983): A technique for radiolabelling DNA restriction endonuclease fragments to high specific activity. Anal Biochem 132:6-13.

Fialkow PJ (1973): Primordial cell pool size and linkage relationships of five human cell types. Ann Hum Genet 37:39-48. 
Freeman CD Jr (1955): Congenital ectodermal dysplasia and mesodermal dysplasia. AMA Arch Dermatol Syph 71:667.

Freire-Maia N, Pinheiro M (1984): "Ectodermal Dysplasias: A Clinical and Genetic Study." New York: Alan R. Liss, Inc., pp 37-38.

Fryns JP, Dhondt F, Lindermans L, van den Berghe H (1978): Focal dermal hypoplasia (Goltz syndrome) in a male. Acta Paediatr Belg 31:37-39.

Fuscoe JC, Fenwick RG, Ledbetter DH, Caskey CT (1983): Deletion and amplification of the HGPRT locus in Chinese hamster cells. J Mol Cell Biol 3:1086-1096.

Gealy WJ, Dayer JM, Harley JB (1980): Allelic exclusion of glucose-6phosphate dehydrogenase in platelets and lymphocytes-T from a Wiskott-Aldrich syndrome carrier. Lancet 1:63-65.

Ginsberg LD, Sedano HO, Gorlin RJ (1970): Focal dermal hypoplasia syndrome. Am J Roentgenol 110:561-571.

Goltz RW, Peterson WC, Gorlin RJ, Ravits HG (1962): Focal dermal hypoplasia. Arch Dermatol 86:707-711.

Goltz RW, Henderson RR, Hitch JM, Ott JE (1970): Focal dermal hypoplasia syndrome-A review of the literature and report of two cases. Arch Dermatol 101:1-11.

Gorski JL, Stein CK, Glover TW (1989): A somatic cell hybrid panel to facilitate identification of DNA sequences in the vicinity of the incontinentia pigmenti locus (IP1). Cytogenet Cell Genet 52:90-92.

Hall JG (1988): Review and hypotheses: Somatic mosaicism: Observations related to clinical genetics. Am J Hum Genet 43:355-363.

Hendriks RW, Mensink EJBM, Kraakman MEM, Schuurman RKB (1989): Evidence for male X chromosomal mosaicism in X-linked agammablobulinemia. Hum Genet 83:267-270.

Hermann BG, Frischauf A-M (1987): Isolation of genomic DNA. Methods Enzymol 152:180-183.

Kahan B, Held KA, DeMars R (1974): The locus for human adenine phosphoribosyltransferase is on chromosome 16 . Genetics 78:11431156.

Larregue M, Michel Y, Maroteaux J, Degos R, Stewart WM (1971): L'hypoplasie dermique en aires; considérations sur l'osteopathie striée et sur le problème génétigue. Ann Dermatol Syph 98:491500.

Legius E, Baten E, Stul M, Marymen P, Cassiman J-J (1990): Sporadic late onset ornithine transcarbamylase deficiency in a boy with somatic mosaicism for an intragenic deletion. Clin Genet (in press).

Maddalena A, Sosnoski DM, Berry GT, Nussbaum RL (1988): Mosaicism for an intragenic deletion in a boy with mild ornithine transcarbamylase deficiency. N Engl J Med 319:999-1003.

Maniatis T, Fritsch EF, Sambrook J (1982): "Molecular Cloning: A Laboratory Manual." Cold Spring Harbor, NY: Cold Spring Harbor Laboratory.

Migeon BR, Axelman J, Jan de Beur S, Valle D, Mitchell GA, Rosenbaum KN (1989): Selection against alleles in females heterozygous for incontinentia pigmenti. Am J Hum Genet 44:100-106.

Neidich JA, Nussbaum RL, Packer RJ, Emanuel BS, Puck JM (1990): Heterogeneity of clinical severity and molecular lesions in Aicardi syndrome. J Pediatr 116:911-917.

Prchal JT, Carroll AJ, Prchal JF, Rist W, Shalka HW, Gealy WJ, Harley JB, Malluh A (1980): Wiskott-Aldrich syndrome: Cellular impairments and their implications for carrier detection. Blood 56:1048-1054.

Reed KC, Mann DA (1985): Rapid transfer of DNA from agarose gels to nylon membranes. Nucleic Acids Res 13:7207-7221.

Ruiz-Maldonaldo R, Carnevale A, Tamayo L, Montiel EM (1974): Focal dermal hypoplasia. Clin Genet 6:36-45.

Temple IK, Hurst JA, Hing S, Butler L, Baraitser M (1990a): De novo deletion of Xp22.2-pter in a female with linear skin lesions of the face and neck, microphthalmia, and anterior chamber eye anomalies. J Med Genet 27:56-58.

Temple IK, MacDowall P, Baraitser M, Atherton DJ (1990b): Focal dermal hypoplasia (Goltz syndrome). J Med Genet 27:180-187.

Vogelstein B, Fearon E, Hamilton SR, Feinberg AP (1985): Use of restriction fragment length polymorphisms to determine the clonal origin of human tumors. Science 227:642-645.

Wettke-Schafer R, Kantner G (1983): X-linked dominant inherited diseases with lethality in hemizygous males. Hum Genet 64:1-23.

Wieacker P, Zimmer J, Ropers H-H (1985): X inactivation patterns in two syndromes with probable $X$-linked dominant, male lethal inheritance. Clin Genet 28:238-242.

Wodiansky P (1957): Über die Formen der congenitalen poikilodermie. Arch Klin Exp Dermatol 205:331-342. 